\title{
Komagataeibacter rhaeticus grown in sugarcane molasses-supplemented culture medium as a strategy for enhancing bacterial cellulose production
}

\author{
Rachel T.A. Machado ${ }^{a}$, Andréia Bagliotti Meneguin ${ }^{\mathrm{a}, \mathrm{b}}$, Rafael Miguel Sábio ${ }^{\mathrm{a}, *}$, \\ Douglas Faza Franco ${ }^{c}$, Selma G. Antonio ${ }^{c}$, Junkal Gutierrez ${ }^{\mathrm{d}, \mathrm{e}}$, Agnieszka Tercjak ${ }^{\mathrm{d}}$, \\ Andresa A. Berretta ${ }^{f}$, Sidney J.L. Ribeiro ${ }^{c}$, Silmara C. Lazarini ${ }^{a}$, Wilton R. Lustri ${ }^{a}$, \\ Hernane S. Barud ${ }^{\mathrm{a}}$ \\ a University of Araraquara - UNIARA, 14801-320, Araraquara, SP, Brazil \\ ${ }^{\mathbf{b}}$ Interdisciplinary Laboratory of Advanced Materials, Centro de Ciências da Natureza - CNN, Universidade Federal do Piauí - UFPI, 64049-550, Teresina, PI, Brazil \\ ${ }^{\mathrm{c}}$ Institute of Chemistry - São Paulo State University - UNESP, 14800-060, Araraquara, SP, Brazil \\ ' Group 'Materials + Technologies' (GMT), Department of Chemical and Environmental Engineering, Faculty of Engineering, Gipuzkoa, University of the Basque Country \\ (UPV/EHU), Plaza Europa 1, 20018, Donostia-San Sebastián, Spain \\ e Faculty of Engineering Vitoria-Gasteiz, University of the Basque Country (UPV/EHU), C/Nieves Cano 12, 01006, Vitoria-Gasteiz, Spain \\ ${ }^{\mathrm{f}}$ Laboratório de Pesquisa, Desenvolvimento \& Inovação, Apis Flora Ind. Coml. Ltda, Ribeirão Preto, 14020-670, São Paulo, Brazil
}

\section{A R T I C L E I N F O}

\section{Keywords:}

Bacterial cellulose

Sugarcane molasses

Alternative culture medium

Smoother and flexible BC membranes

Cheaper BC production

\begin{abstract}
A B S T R A C T
Komagataeibacter rhaeticus, a bacterium isolated from Kombucha tea, was used to produce bacterial cellulose (BC) through its cultivation in a static sugarcane molasses (SCM) supplemented-culture medium (totally or partially), as an alternative carbon source. BC membranes were characterized by different physicochemical analysis using Fourier transform infrared spectroscopy (FTIR), X-ray diffraction (XRD), field emission gunscanning electron microscopy (FEG-SEM), thermogravimetry analysis (TGA) and PeakForce quantitative nanomechanics atomic force microscopy (PeakForce (QNM-AFM)). FTIR, XRD and TGA results suggest great similarity among all membranes produced by distinct culture media. Although the glucose (F1) and SCM (F6) media presented the lowest BC yield, all SCM-supplemented culture media (from F2 to F5) showed BC yield values similar to the HS culture medium (F0). FEG-SEM analysis showed that as higher SCM concentrations on culture media higher dense nanofibers network could be prepared. Quantitative nanomechanical results obtained by AFM technique corroborate FEG-SEM analysis besides show smoother and more flexible BC membranes as a function of the increasing of the SCM concentrations. The modification of the carbon source of the culture medium with an important by-product of Brazilian agroindustry appears as a viable alternative to reduce cost of BC production (of up to $20.06 \%$ ) besides increase the possibilities of industrial scale BC preparation.
\end{abstract}

\section{Introduction}

Cellulose $\left(\mathrm{C}_{6} \mathrm{H}_{10} \mathrm{O}_{5}\right)$ - a linear high molecular weight homopolysaccharide with $\beta-1.4$ glycosidic bonds formed after the polymerization of anhydroglucose units - has received much attention in recent years in different research areas, mainly for biomedical and pharmaceutical applications, as it is the most abundant renewable biopolymer on Earth, reaching 1 trillion tons in nature and showing an increase of approximately 100 billion tons per year as a result of photosynthesis (Klemm et al., 2005). In addition to this, the applications versatility of cellulose is related to its various sources, as well as physical, chemical or enzymatic treatments which led to materials with different properties concerning purity, crystallinity, surface reactivity, crystal structure, morphology, and others.

Regarding the heterogeneous sources of cellulose, it can be synthesized from Plantae and Animalia kingdoms and Eubacteria domain, so that cellulose obtained retains unique similar properties, such as high mechanical strength and stiffness, biodegradability and renewability, which are mainly related to the ability of hydroxyl groups to form supramolecular interactions of the type intra- and intermolecular

\footnotetext{
* Corresponding author.

E-mail addresses: racheltemperani@gmail.com (R.T.A. Machado), abagliottim@hotmail.com (A.B. Meneguin), rafaelmsabio@gmail.com (R.M. Sábio), fazafranco@yahoo.com.br (D.F. Franco), selma_ga@yahoo.com.br (S.G. Antonio), juncal.gutierrez@ehu.eus (J. Gutierrez), agnieszka.tercjaks@ehu.eus (A. Tercjak), andresa.berretta@apisflora.com.br (A.A. Berretta), sjlribeiro@gmail.com (S.J.L. Ribeiro), silmaralazarini8@yahoo.com.br (S.C. Lazarini), wrlustri@yahoo.com.br (W.R. Lustri), hernane.barud@gmail.com (H.S. Barud).
} 
hydrogen bonds, leading to the structural packaging of cellulose in a fibrillar and semicrystalline form (Jorfi and Foster, 2015; Kolakovic et al., 2012).

Among different types of cellulose, bacterial cellulose (BC) or nanocellulose, obtained as a gel-like three-dimensional mat, is noteworthy by presenting unique features, such as high degree of crystallinity (above 60\%), increased Young's modulus (up to $15 \mathrm{GPa}$ ), tensile strength (200-300 MPa), high thermal stability (decomposition temperature ranging from 340 to $370{ }^{\circ} \mathrm{C}$ ), elasticity and porosity (Grande et al., 2009; Klemm et al., 2005). In addition, its high surface area allows the absorption of large amounts of liquids, strong interactions with other polymers and biomaterials, enzymes and nanoparticles.

Although BC can be produced by a number of gram-negative bacteria, Gluconacetobacter xylinus (G. xylinus) has received much attention over the years for producing BC in commercial quantities from different carbon and nitrogen sources (Klemm et al., 2005; Sheykhnazari et al., 2011). However, this fact highlights the great need for searching other superproductive bacteria in order to maximize the $\mathrm{BC}$ production and make it more economically competitive.

Recently, Machado et al. (2016) and Dos Santos et al. (2014) isolated a strain from Kombucha tea for BC production, which occurred in a rate $50 \%$ higher, besides showing similar physicochemical, morphological and mechanical properties than those BC synthesized by $G$. $x y$ linus. This set of findings makes the Komagataeibacter rhaeticus a more viable alternative for $\mathrm{BC}$ production, leading to benefits that range from time production optimization to costs reduction.

Assuming the elevate costs of $\mathrm{BC}$ production mainly related to the expensive culture media, which can reach up to $30 \%$ of the total production cost (Çakar et al., 2014; Jozala et al., 2015), another point that has been widely discussed is about the search for alternative culture media to the conventional Hestrin and Schramm (1954), which uses glucose as carbon source. To date, several alternative substrates has been proposed, aiming to find cheaper and more efficient carbon and/ or nitrogen sources, such as pineapple agroindustrial residues (Algar et al., 2015), grape extract (Rani et al., 2011), coffee cherry husk (Rani and Apppaiah, 2013), pineapple, pomegranate, muskmelon, watermelon, tomato and orange fruits (Hungund et al., 2013), and others.

Sugarcane molasses (SCM) is a by-product of sugar production that has great amounts of fermentable sugars as fructose, sucrose and glucose, reason why it has been considered the most economical carbon source in the fermentation industry. According to Tyagi and Suresh (2016), molasses also has nitrogen and vitamins sources, which may play an important role in optimizing the production of BC. Aggregating value to the SCM is of major importance in Brazil, since this country represents not only the first position in the ranking of sugarcane-producing countries, but also of sugar and ethanol (BRASIL, 2016).

Some authors have already described the production of BC in molasses using different bacteria, such as Zoogloea sp (Paterson-Beedle et al., 2000; Pinto et al., 2016), Gluconacetobacter xylinus FC01 (Çakar et al., 2014), Gluconacetobacter intermedius SNT-1 (Tyagi and Suresh, 2013, 2016), and Acetobacter xylinum subsp. sucrofermentans BRP2001 (Bae and Shoda, 2004, 2005). However, no report has been recorded up to now about the important association Komagataeibacter rhaeticus and sugarcane molasses.

Hence, the investigation of BC production by $K$. rhaeticus bacterium isolated of Kombucha tea and grown in static SCM-supplemented culture media were evaluated in order to reach an alternative carbon source, in addition to adding value to this important by-product of Brazilian agroindustry. As already described by Machado et al. (2016), comparative studies using both G. xylinus and $K$. rhaeticus showed BC membranes produced with similar physicochemical, morphological, thermal and mechanical properties. From these results, $K$. rhaeticus emerged as a suitable and viable alternative bacterium to produce $\mathrm{BC}$ membranes. Herein, we have proposed to evaluate BC production by $K$. rhaeticus in supplemented HS culture medium by adding SCM as alternative and cheaper carbon source (totally or partially).

\section{Materials and methods}

\subsection{Materials}

Anhydrous D-glucopyranose and ethanol, citric acid, $\mathrm{KH}_{2} \mathrm{PO}_{4}$, $\mathrm{Na}_{2} \mathrm{HPO}_{4}, \mathrm{MgSO}_{4} \cdot 7 \mathrm{H}_{2} \mathrm{O}$, all P.A. grade were purchased from Synth . Bacteriologic peptone, agar and yeast extract were purchased from Merck. Sugarcane molasses (SCM) composed by sucrose (57.8\%), glucose $(5.2 \%)$, fructose $(6.5 \%)$ and other noncarbohydrate substances (15.8\%), as previously described by Lazarini et al. (2016), were supplied by Santa Cruz sugar and alcohol industry (from Americo Brasiliense-São Paulo, Brazil). Komagataeibacter rhaeticus (Dos Santos et al., 2014) was the bacteria used for BC production.

\subsection{Methods}

\subsubsection{Isolation of Komagataeibacter rhaeticus bacterium}

$K$. rhaeticus bacterium was isolated from Kombucha tea according to Dos Santos et al. (2014). Briefly, $100 \mathrm{~mL}$ of Kombucha starter was mixed with $1 \mathrm{~L}$ of a cooled tea containing $40 \mathrm{~g}$ of sucrose and $20 \mathrm{~g}$ of green tea, and after the set was incubated for 10 days at $30^{\circ} \mathrm{C}$. For the isolation of $K$. rhaeticus, Kombucha tea was diluted (1:10) in sterile $0.9 \mathrm{wt} \% \mathrm{NaCl}$ solution, followed by a serial dilution in ten tubes, of which aliquots were plated in Petri dishes containing HS culture medium $(20 \mathrm{~g} / \mathrm{L}$ de glucose, $5 \mathrm{~g} / \mathrm{L}$ de peptone, $5 \mathrm{~g} / \mathrm{L}$ yeast extract, $2.7 \mathrm{~g} / \mathrm{L}$ of $\mathrm{Na}_{2} \mathrm{HPO}_{4}, 115 \mathrm{~g} / \mathrm{L}$ of citric acid, $15 \mathrm{~g} / \mathrm{L}$ of agar, $\mathrm{pH}$ 5) (Hestrin and Schramm, 1954). The plates were incubated at $30^{\circ} \mathrm{C}$ for 5 days. The suspect colonies were seeded on HS medium and incubated again as described above. After the incubation period, one isolated colony was transferred to test tubes $(20 \times 150 \mathrm{~mm})$ containing HS broth and incubated at $30^{\circ} \mathrm{C}$ for five days, in order to evaluate the production of cellulose, which can be easily observed on the surface of the culture medium. The cellulose producer was identified as $K$. rhaeticus and after have its genome sequenced on the Illumina HiSeq2000 system, generating 44,413,164 paired-end reads of 100 bp (insert size, 250bp) (Dos Santos et al., 2014).

\subsubsection{BC production in different composition culture medium}

A pre-inoculum was prepared from one isolated colony in a $100 \mathrm{~mL}$ Erlenmeyer flask containing $50 \mathrm{~mL}$ of sterile HS broth, which were incubated at $30^{\circ} \mathrm{C}$ for $24 \mathrm{~h}$. For the BC production, $5 \mathrm{~mL}$ of pre-inoculum (K. rhaeticus) was added in a $250 \mathrm{~mL}$ Erlenmeyer flask containing $45 \mathrm{~mL}$ of HS culture medium (F0), composed by $50 \mathrm{~g} / \mathrm{L}$ of glucose, $4 \mathrm{~g} / \mathrm{L}$ of yeast extract, $0.73 \mathrm{~g} / \mathrm{L}$ of $\mathrm{MgSO}_{4} \cdot 7 \mathrm{H}_{2} \mathrm{O}, 2 \mathrm{~g} / \mathrm{L}$ of $\mathrm{KH}_{2} \mathrm{PO}_{4}, 20 \mathrm{~g} / \mathrm{L}$ of ethanol and distilled water, $1000 \mathrm{~mL}$, as standard media. The base medium composed by carbon sources (glucose and/or SCM), yeast extract ( $4 \mathrm{~g} / \mathrm{L})$, ethanol $(20 \mathrm{~g} / \mathrm{L})$ and labeled as F1 (50 g/L of glucose), F2 ( $40 \mathrm{~g} / \mathrm{L}$ of glucose plus $10 \mathrm{~g} / \mathrm{L}$ of SCM), F3 (30 g/L of glucose plus $20 \mathrm{~g} /$ $\mathrm{L}$ of SCM), F4 (20 g/L of glucose plus $30 \mathrm{~g} / \mathrm{L}$ of SCM), F5 (10 g/L of glucose plus $40 \mathrm{~g} / \mathrm{L}$ of SCM) and F6 (50 g/L of SCM). The media were autoclaved for $20 \mathrm{~min}$ at $121{ }^{\circ} \mathrm{C}$.

The different medium containing the bacterial inoculum were incubated in static conditions in $250 \mathrm{~mL}$ Erlenmeyer flask, at $30^{\circ} \mathrm{C}$ for $120 \mathrm{~h}$. BC membranes produced were submitted to the purification process by treating them with $0.5 \mathrm{M} \mathrm{NaOH}$ solution at $80^{\circ} \mathrm{C}$ for $30 \mathrm{~min}$, followed by successive washes until neutral $\mathrm{pH}$ 7.0.

Take into account the cost of each component to obtain $1000 \mathrm{~mL}$ from distinct culture media, the culture media average costs (in dollar) and reduction percent (\%) were calculated for F0-F6 media comparing with standard medium (HS medium). It is worth emphasizing that the calculated costs do not involve further BC purification steps.

\subsection{3. $B C$ yield}

$\mathrm{BC}$ production was recorded as dry weight of $\mathrm{BC}$ within the volume of medium $(\mathrm{g} / \mathrm{L})$. For this, BC membranes were completely oven dried at $37^{\circ} \mathrm{C}$ for $24 \mathrm{~h}$. Next, mass measurements were performed in 
quintuplicate using a Shimadzu analytical balance (to four decimal places precision) at $25^{\circ} \mathrm{C}$.

\subsubsection{Water holding capacity}

The wet BC membranes cultivated at media with carbon sources variations, (F0, F1, F2, F3, F4, F5 and F6), were weighted. Subsequently, wet BC sheets were dried under vacuum at $37^{\circ} \mathrm{C}$ for $12 \mathrm{~h}$ in an oven. Five samples of each different medium were analysed. The water holding capacity (WHC) was calculated by the following formula (Machado et al., 2016; Shezad et al., 2010):

WHC $=\frac{\text { mass of water removed during drying }(\mathrm{g})}{\text { dry mass of membrane }(\mathrm{g})}$

\subsubsection{Field emission gun-scanning electron microscopy (FEG-SEM)}

FEG-SEM images of BC membranes were obtained in a field emission scanning electron microscope JEOL JSM-7500F, so that surface photomicrographs were taken at $30,000 \times$ magnification. All samples were examined using an accelerating voltage of $10 \mathrm{kV}$.

\subsubsection{Fourier transformed infrared spectroscopy (FTIR)}

FTIR spectra of BC membranes were acquired using a Perkin Elmer Spectrum 100 spectrometer in ATR mode. The spectra were collected over the range of $4000-400 \mathrm{~cm}^{-1}$ with an accumulation of 32 scans, resolution of $4 \mathrm{~cm}^{-1}$ and interval of $0.5 \mathrm{~cm}^{-1}$.

\subsubsection{X-ray diffraction $(X R D)$}

The X-ray diffraction analysis were performed on a X-ray diffractometer (Siemens 246 - Model D5000; Germany), using nickel filtered $C u K_{\alpha}$ radiation $(\lambda=1.5406 \AA$ ) (tube operating at $40 \mathrm{kV}$ and $30 \mathrm{~mA}$ ). Scanning regions were collected between 4 and $50^{\circ}(2 \theta)$ in step size of $0.02^{\circ}(2 \theta)$.

Crystallinity index (CrI) of the BC membranes was calculated according to Segal method (Eq. (1)) (Segal et al., 1959), as follows:

$C r I=\left(\frac{I_{200}-I_{a m}}{I_{200}}\right) \times 100$

\subsubsection{Thermogravimetric analysis (TG/DTG)}

TG/DTG analysis were performed via a TA SDT 2960 (TA Instruments, USA) at a heating rate of $10^{\circ} \mathrm{C} / \mathrm{min}$, from 25 to $600^{\circ} \mathrm{C}$, under oxygen atmosphere (flow rate of $50 \mathrm{~mL} / \mathrm{min}$ ), in open aluminum pans containing about $5 \mathrm{mg}$ of sample.

\subsubsection{PeakForce quantitative nanomechanics atomic force microscopy (PeakForce (QNM-AFM))}

Mechanical properties at nanoscale of $\mathrm{BC}$ membranes prepared in different culture media were analyzed by PeakForce quantitative nanomechanical property mapping (PeakForce QNM) using Dimension Icon microscope from Bruker. Measurements were carried out in PeakForce mode under ambient conditions. A silicon tip with nominal radius of $10 \mathrm{~nm}$, cantilever length of $125 \mu \mathrm{m}$, and resonance frequency of $150 \mathrm{kHz}$ was used. The measurements were performed with a calibrated optical sensitivity. The exact spring constant of the tip was calculated using the Thermal Tune option and a defined tip radius was adjusted using PS as standard.

\subsubsection{Statistical analysis}

When applied, the results were treated by one-way analysis of variance to assess the significance of the differences between data. Tukey-Kramer post-test was used to compare the means of different treatment data (Graph Pad Prism 5.0 software). Results with $\mathrm{p}<0.05$ were considered statistically significant.

\section{Results and discussion}

\subsection{Cost production}

The high cost of culture media for BC production lead us to propose some strategies to overcome this drawback aiming its industrial production. So, the use of residues or by-products from agroforest and food industry as carbon and nitrogen sources for new compositions of culture media allow us to reduce the cost of $\mathrm{BC}$ production besides maintaining the high quality of produced BC (Pacheco et al., 2017). Jahan et al. (2018) showed that using crude distillery effluent the maximum of BC production by Gluconacetobacter oboediens was $8.5 \mathrm{~g} / \mathrm{L}$. The use of glycerol and grape bagasse residues as carbon sources obtained from biodiesel and wine production, respectively (in media containing corn steep liquor as nitrogen source), presented a maximum BC production from 8 to $10 \mathrm{~g} / \mathrm{L}$ (Vazquez et al., 2013). Tyagi and Suresh (2013) described the production of BC in pre-treated molasses as supplement in HS medium by Gluconacetobacter intermedius NT obtained from orange pulp. The maximum BC production achieved was $3.5 \mathrm{~g} / \mathrm{L}$ under static conditions for 10 days. Regarding to BC production costs, Pacheco et al. (2017) reported that modifying the culture media using cashew residues, a cost reduction in BC production from 16.5 to $33 \%$ were achieved relating to the conventional HS medium. In this sense, sugarcane molasses (SCM) as nutrient sources originated from agroindustrial residues have been proposed. F0, F1 and F6 correspond to HS, glucose and SCM media, respectively. From F2 to F5, distinct compositions of culture media were evaluated using different SCM concentrations. The production average cost and reduction percent were calculated from the conventional nutrient source (HS culture medium) to compare all culture media as shown in Table 1 . The introduction of SCM as nutrient source promoted a significant costs reduction of culture media from 7.35 to $20.06 \%$ (from F2 to F6 media) regarding the HS culture medium and, consequently, the cost of BC production. These results suggest the molasses-supplemented culture media a viable way for escalation processes of BC production.

\subsection{BC yield}

The effect of different SCM-supplemented culture media on the BC production were evaluated using $\mathrm{BC}$ yield results as shown in Fig. 1. The BC yield varied with the concentration of the carbon sources (glucose and/or SCM) present in the culture media (from F0 to F6). It is worth emphasizing that BC membranes produced by $K$. rhaeticus presented similar BC yield in all SCM-supplemented media, specifically for F2-F5 ( $\mathrm{p}>0.05$ ) culture media showing average BC yield of 3.88, 4.01, 3.72 and $3.46 \mathrm{~g} / \mathrm{L}$, respectively. Remarkably, the glucose partial substitution by the nutrient sources present in molasses (sucrose, fructose and glucose) do not affect the $\mathrm{BC}$ production capacity (relating to HS medium) been a highly viable way to reduce costs of $\mathrm{BC}$ production using agroindustrial residues as nutrient sources. In addition,

Table 1

Average cost (in dollar) and reduction percent from distinct culture media $(1 \mathrm{~L})$ for BC production.

\begin{tabular}{|c|c|c|}
\hline Culture media (1 L) & Average cost (\$) & Reduction percent (\%) \\
\hline F0 (HS medium) & 2.78 & - \\
\hline F1 (glucose medium) & 2.74 & 1.69 \\
\hline $\begin{array}{l}\text { F2 }(40 \mathrm{~g} / \mathrm{L} \text { of glucose plus } 10 \mathrm{~g} / \mathrm{L} \text { of } \\
\text { SCM })\end{array}$ & 2.58 & 7.35 \\
\hline $\begin{array}{l}\text { F3 (30 g/L of glucose plus } 20 \mathrm{~g} / \mathrm{L} \text { of } \\
\text { SCM) }\end{array}$ & 2.49 & 10.53 \\
\hline $\begin{array}{l}\text { F4 (20 g/L of glucose plus } 30 \mathrm{~g} / \mathrm{L} \text { of } \\
\text { SCM) }\end{array}$ & 2.40 & 13.70 \\
\hline $\begin{array}{l}\text { F5 }(10 \mathrm{~g} / \mathrm{L} \text { of glucose plus } 40 \mathrm{~g} / \mathrm{L} \text { of } \\
\text { SCM })\end{array}$ & 2.31 & 16.88 \\
\hline F6 $(50 \mathrm{~g} / \mathrm{L}$ of $\mathrm{SCM})$ & 2.23 & 20.06 \\
\hline
\end{tabular}




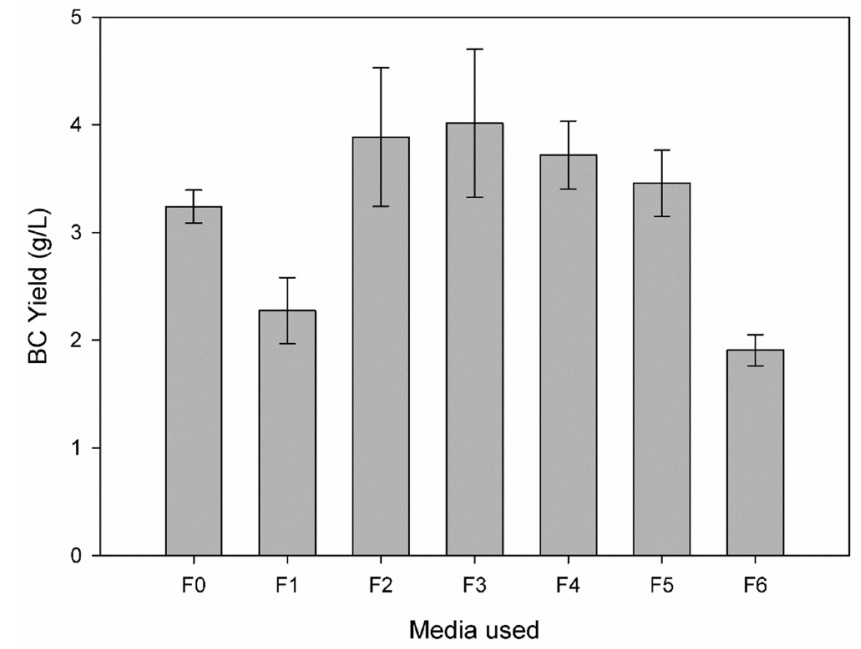

Fig. 1. BC yield (g/L) from F0 (BC produced from HS medium), F1 (50 g/L of glucose); F2 (40 g/L of glucose plus $10 \mathrm{~g} / \mathrm{L}$ of SCM), F3 (30 g/L of glucose plus $20 \mathrm{~g} / \mathrm{L}$ of SCM), F4 (20 g/L of glucose plus $30 \mathrm{~g} / \mathrm{L}$ of SCM), F5 (10 g/L of glucose plus $40 \mathrm{~g} / \mathrm{L}$ of SCM) and F6 (50 g/L of SCM) culture media.

BC yield for the culture media containing only glucose or molasses as carbon sources $(\mathrm{F} 1=2,27 \mathrm{~g} / \mathrm{L}$ and $\mathrm{F} 6=1.90 \mathrm{~g} / \mathrm{L}$, respectively) were statistically similar $(\mathrm{p}>0.05)$ but lower than for the molasses-supplemented culture media (from F2 to F5) ( $<<0.05$ ). These results suggest a synergic effect between the sugars present in molasses besides the presence of other components such as vitamins, amino acids, nucleic acids and minerals which can increase the BC yield. Premjet et al. (2007) described the effect of SCM ingredients on BC production by Acetobacter xylinum ATCC 10245. The authors confirmed SCM as effective culture medium showing the importance of each mainly component (sucrose, glucose and fructose) and its association (sucrose + fructose, fructose + glucose, and others) to increase BC yield. Additionally, it was demonstrated that other components present in SCM as amino acids, nucleic acids, vitamins, ash and others provided higher BC yield relating to the other evaluated media.

\subsection{Water holding capacity}

Water content evaluation is crucial to corroborate structural characterization besides determine its application such as wound dressing (Czaja et al., 2006; Lin et al., 2016). Fig. 2 displays WHC results for BC membranes produced on different culture media (from F0 to F6).

It is worth noting that BC membranes that showed the lowest BC yield (F0, F1 and F6 culture media) were the same that displayed larger WHC values $(\mathrm{p}>0.05)$, indicating that WHC values are directly related to the BC yield. As described by Tsouko et al. (2015), the variation of WHC depend on the BC porosity and surface area. The amount of water trapped on $\mathrm{BC}$ nanofibers increase as a function of the increase of BC porosity and, consequently, BC surface area (Tsouko et al., 2015). Remarkably, WHC values are relating to the formation and structure of the BC nanofibers according to Czaja et al. (2006). Additionally, the nanofibers structure formation are directly dependent on the BC production parameters as nutrient sources (sucrose, glucose, fructose, vitamins, amino acids and others) and others conditions of culture media (Chawla et al., 2009; Lazarini et al., 2016; Keshk, 2014).

\subsection{FEG-SEM}

Fig. 3 displays FEG-SEM images of HS culture medium (F0), BC membranes produced by glucose/SCM-supplemented culture media (F1-F5) and for the SCM-supplemented culture medium (F6), respectively. All samples showed heterogeneous three-dimensional network

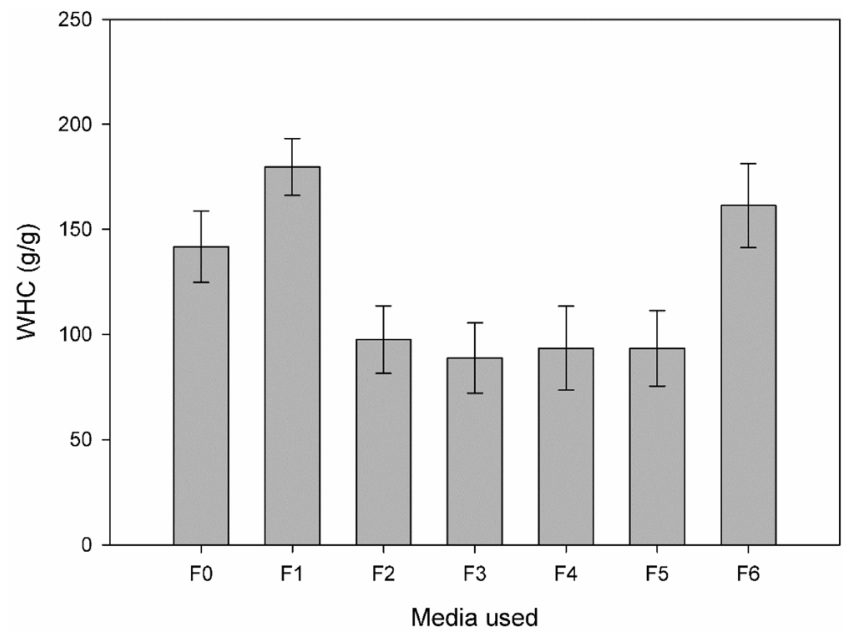

Fig. 2. Water holding capacity (WHC) from F0 (BC produced from HS medium), F1 (50 g/L of glucose); F2 (40 g/L of glucose plus $10 \mathrm{~g} / \mathrm{L}$ of SCM), F3 (30 g/L of glucose plus $20 \mathrm{~g} / \mathrm{L}$ of SCM), F4 (20 g/L of glucose plus $30 \mathrm{~g} / \mathrm{L}$ of SCM), F5 $(10 \mathrm{~g} / \mathrm{L}$ of glucose plus $40 \mathrm{~g} / \mathrm{L}$ of SCM) and F6 (50 g/L of SCM) culture media.

porous structure composed by randomly arranged cellulose nanofibers without relevant differences among the nanofibers arrangement obtained from different percentage and types of carbon sources (Fig. 3F1-F5) (Çakar et al., 2014; Pacheco et al., 2017). However, BC membranes produced in HS medium (Fig. 3F0) presented thin nanofibers and, consequently, less dense nanofibers structure comparing to $\mathrm{BC}$ membranes produced in SCM medium (Fig. 3F6) corroborating BC yield and WHC results (Velásquez-Riaño and Bojacá, 2017; Lazarini et al., 2016; Machado et al., 2016; Çakar et al., 2014). The average nanofiber thickness were 92 and $119 \mathrm{~nm}$ for F0 and F6 samples, respectively.

\subsection{FTIR}

Fig. 4 shows FTIR spectra of BC produced by HS culture medium (F0), BC membranes produced by glucose/SCM-supplemented culture media (F1-F5) and for the SCM-supplemented culture medium (F6), respectively. Table 2 highlights the main $\mathrm{BC}$ vibrational modes (Barud et al., 2008a, 2011). The FTIR spectra (Fig. 4F1-F5) showed that the glucose/SCM-supplementation does not change the spectral profile of the membranes when compared to the FTIR spectrum (F0) of the HS culture medium, indicates the absence of by-products and impurities on the BC membranes.

The FTIR spectra of all BC analyzed present a broadband at $3340 \mathrm{~cm}^{-1}$ assigned to the stretching of the hydroxyl groups $(\mathrm{O}-\mathrm{H}$ bonds) (Barud et al., 2008a, 2011). In this case, it should be to highlighted that the main difference between the SCM-supplementation (spectra F1-F5) and the HS membrane (spectrum F0) is the band intensity increase at $1030 \mathrm{~cm}^{-1}$ assigned to $v_{s}(C-O)$ of primary alcohol as a function of the SCM-supplementation increase, especially for the spectra F4 and F5, 30 and $40 \mathrm{~g} / \mathrm{L}$ of SCM, respectively.

\section{6. $X R D$}

The X-ray diffraction measurements were carried out to evaluate the crystalline structure BC obtained from different culture media. Fig. 5 displays XRD patterns of $\mathrm{BC}$ membranes produced by HS culture medium (F0), BC membranes produced by glucose/SCM-supplemented culture media (F1-F5) and for the SCM-supplemented culture medium (F6), respectively. Three characteristic peaks were observed for all BC membranes at $2 \theta$ angles of approximately $14.7^{\circ}, 16.9^{\circ}$ and $22.9^{\circ}$, which correspond to the primary diffraction of (101), (101) and (200) planes of native BC type I (De Salvi et al., 2014; Tercjak et al., 2015, 2016). The changes in the relative peak intensity at $2 \theta$ of $14.7^{\circ}$ could be related 

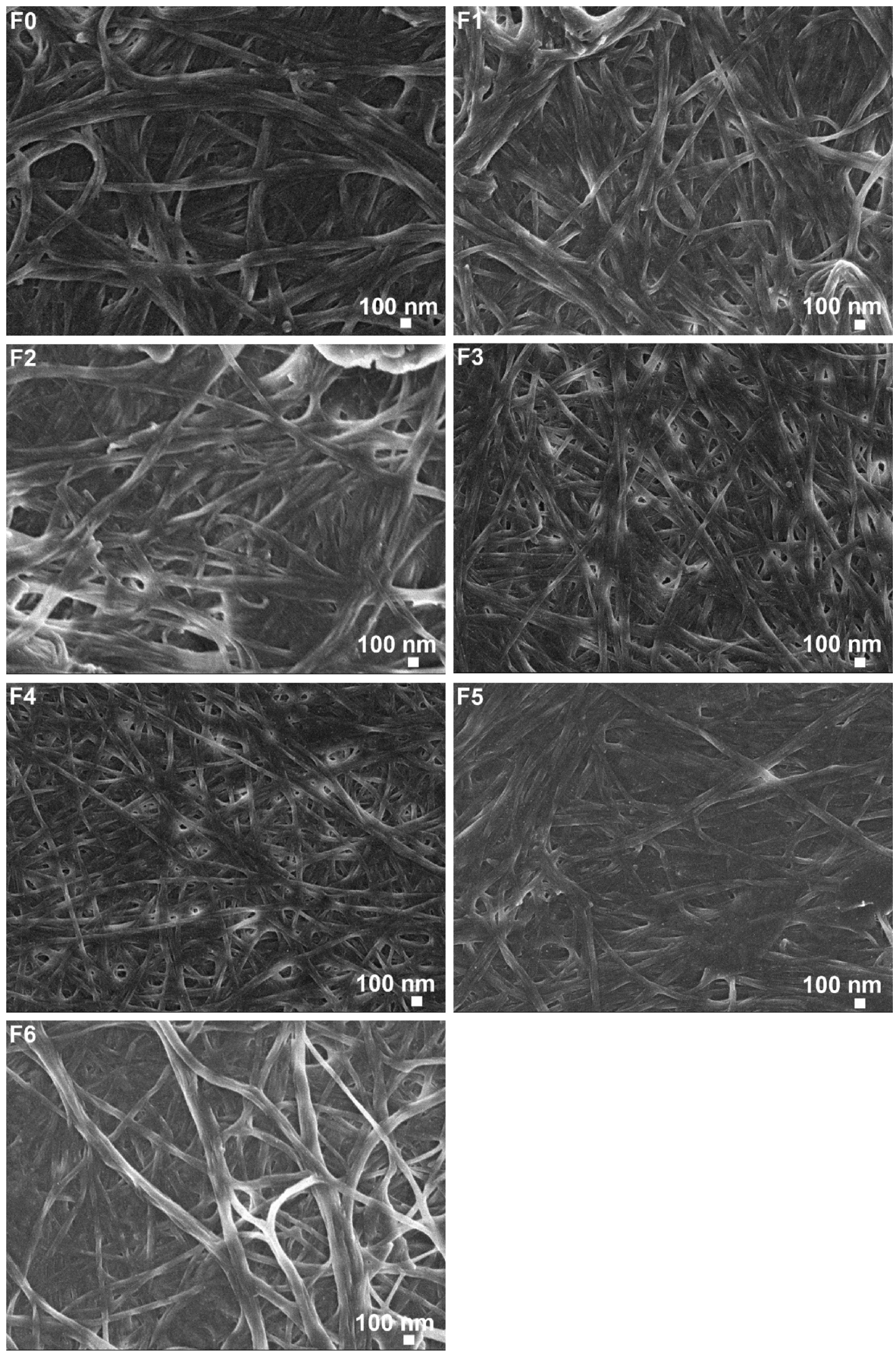

Fig. 3. FEG-SEM images of BC produced in distinct culture media, where F0 corresponds to BC produced from HS medium; F1 (50 g/L of glucose); F2 (40 g/L of glucose plus $10 \mathrm{~g} / \mathrm{L}$ of SCM); F3 (30 g/L of glucose plus $20 \mathrm{~g} / \mathrm{L}$ of SCM); F4 (20 g/L of glucose plus $30 \mathrm{~g} / \mathrm{L}$ of SCM); F5 (10 g/L of glucose plus $40 \mathrm{~g} / \mathrm{L}$ of SCM) and F6 (50 $\mathrm{g} / \mathrm{L}$ of SCM). 


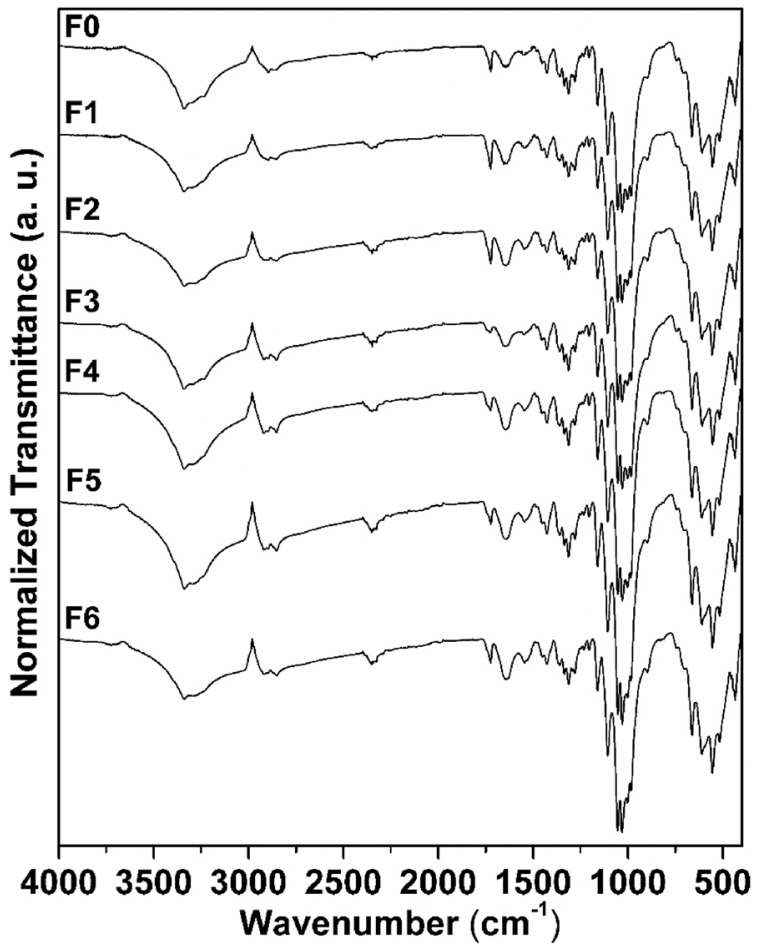

Fig. 4. FTIR spectra of $B C$ produced in distinct culture media, where F0 corresponds to BC produced from HS culture medium; F1 (50 g/L of glucose); F2 ( $40 \mathrm{~g} / \mathrm{L}$ of glucose plus $10 \mathrm{~g} / \mathrm{L}$ of SCM); F3 (30 g/L of glucose plus $20 \mathrm{~g} / \mathrm{L}$ of SCM); F4 (20 g/L of glucose plus $30 \mathrm{~g} / \mathrm{L}$ of SCM); F5 (10 g/L of glucose plus $40 \mathrm{~g} / \mathrm{L}$ of SCM) and F6 (50 g/L of SCM).

Table 2

Assignment of the main Infrared absorption bands of the Bacterial Cellulose (BC) (Barud et al., 2008a, 2011).

\begin{tabular}{ll}
\hline $\begin{array}{l}\text { Wavenumber }\left(\mathrm{cm}^{-1}\right) \\
\text { Bacterial Cellulose }(\mathrm{BC})\end{array}$ & Assignments \\
\hline $3340(\mathrm{~s})$ & $\mathrm{O}-\mathrm{H}$ stretching \\
2894 & $\mathrm{CH}$ stretching of $\mathrm{CH}_{2}$ and $\mathrm{CH}_{3}$ groups \\
$1725(\mathrm{~s})$ & $\mathrm{C}=\mathrm{O}$ stretching of acetyl or carboxylic acid \\
1642 & $\mathrm{H}-\mathrm{O}-\mathrm{H}$ bending of absorbed water \\
1427 & $\mathrm{CH}$ bending or $\mathrm{OH}$ in plane bending \\
1370 & $\mathrm{C}-\mathrm{H}$ deformation $\mathrm{CH}_{3}$ or OH bending) \\
1165 & $\mathrm{C}-\mathrm{O}-\mathrm{C}$ antisymmetric bridge stretching \\
$1030(\mathrm{~s})$ & $\mathrm{C}-\mathrm{O}$ symmetric stretching of primary alcohol \\
$897(\mathrm{w})$ & $\beta$ glucosidic linkages between the sugar units
\end{tabular}

vs (symmetric stretching), s (strong) and w (weak).

to slightly difference on chains orientation for all BC membranes (Castro et al., 2011).

Table 3 exhibits the relative degree of crystallinity of BC membranes expressed as described by Segal et al. (1959). The $\mathrm{I}_{200}$ is the maximum intensity (in arbitrary units) of the plane 200 and $\mathrm{I}_{\mathrm{am}}$ is the intensity of diffraction in the same units at $2 \theta$ angle $18.0^{\circ}$ (Pacheco et al., 2017; Segal et al., 1959). The degree of crystallinity obtained from F0 to F6 membranes fluctuated between $1-3 \%$, which suggests that using different percentage and distinct carbon sources (SCM and glucose) the crystallinity values remains quite similar.

\subsection{Thermal behavior}

Fig. 6 displays TG/DTG curves obtained from F0-F6 membranes. Two main events were detected for all $\mathrm{BC}$ membranes. The first one, up to about $150{ }^{\circ} \mathrm{C}$ corresponds to approximately $5 \%$ of weight loss, attributed to loss of physically adsorbed water (dehydratation of $\mathrm{BC}$

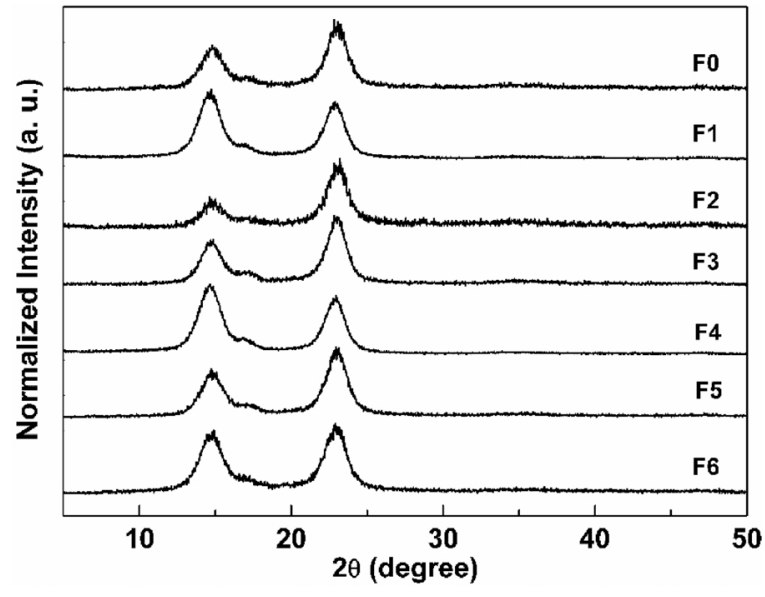

Fig. 5. X-ray diffraction of BC produced in distinct culture media, where F0 corresponds to BC produced from HS medium; F1 (50 g/L of glucose); F2 (40 g/ $\mathrm{L}$ of glucose plus $10 \mathrm{~g} / \mathrm{L}$ of SCM); F3 (30 g/L of glucose plus $20 \mathrm{~g} / \mathrm{L}$ of SCM); F4 $(20 \mathrm{~g} / \mathrm{L}$ of glucose plus $30 \mathrm{~g} / \mathrm{L}$ of SCM); F5 (10 g/L of glucose plus $40 \mathrm{~g} / \mathrm{L}$ of SCM) and F6 (50 g/L of SCM).

Table 3

Degree of crystallinity obtained from F0 (BC produced from HS medium); F1 (50 g/L of glucose); F2 (40 g/L of glucose plus $10 \mathrm{~g} / \mathrm{L}$ of SCM); F3 (30 g/L of glucose plus $20 \mathrm{~g} / \mathrm{L}$ of SCM); F4 $(20 \mathrm{~g} / \mathrm{L}$ of glucose plus $30 \mathrm{~g} / \mathrm{L}$ of SCM); F5 (10 g/L of glucose plus $40 \mathrm{~g} /$ $\mathrm{L}$ of SCM) and F6 (50 g/L of SCM).

\begin{tabular}{ll}
\hline Samples & Crystallinity (\%) \\
\hline F0 & 89 \\
F1 & 88 \\
F2 & 88 \\
F3 & 89 \\
F4 & 88 \\
F5 & 88 \\
F6 & 86 \\
\hline
\end{tabular}

membranes). The thermal degradation of $\mathrm{BC}$ membranes occurs in two subsequent steps: first step of weight loss in the range of $200-400{ }^{\circ} \mathrm{C}$ (of around $60 \%$ ) were ascribed to the $\mathrm{BC}$ depolymerization in small glucose units. The second step from 400 to $600{ }^{\circ} \mathrm{C}$ (about 20\%) corresponds to the dehydration and decomposition of the glucose units into gases (water, carbon monoxide and carbon dioxide) (Barud et al., 2008b, 2011; De Salvi et al., 2014; Machado et al., 2016). It is worth pointing up that the $\mathrm{T}_{\text {onset }}$ (around $350^{\circ} \mathrm{C}$ ) obtained from DTG curves (Fig. 6, dashed lines) indicate that for all culture media (supplemented or unsupplemented) the produced $\mathrm{BC}$ membranes showed similar thermal stability. Additionally, the absence of residues at $600^{\circ} \mathrm{C}$ confirm that all $\mathrm{BC}$ membranes were obtained without inorganic salts, sodium hydroxide or impurities.

\subsection{PeakForce (QNM-AFM)}

Quantitative nanomechanical properties, analyzed by AFM in PeakForce mode, of BC produced from HS culture media and different SCM-supplemented culture media are shown in the Fig. 7. Similarly, as for FEG-SEM measurements, PeakForce QNM height images of all investigated $\mathrm{BC}$ membranes confirm formation of three-dimensional $\mathrm{BC}$ fibers network independently on the culture media used for BC production (Machado et al., 2016; Tercjak et al., 2016). The visual difference between BC produced using different media can be distinguished if compare their PeakForce QNM height images (Fig. 7F0I-F6I). As shown in the inset of each Fig. 7F0I-F6I, the average roughness $\left(R_{a}\right)$, extracted from PeakForce QNM height images of each 

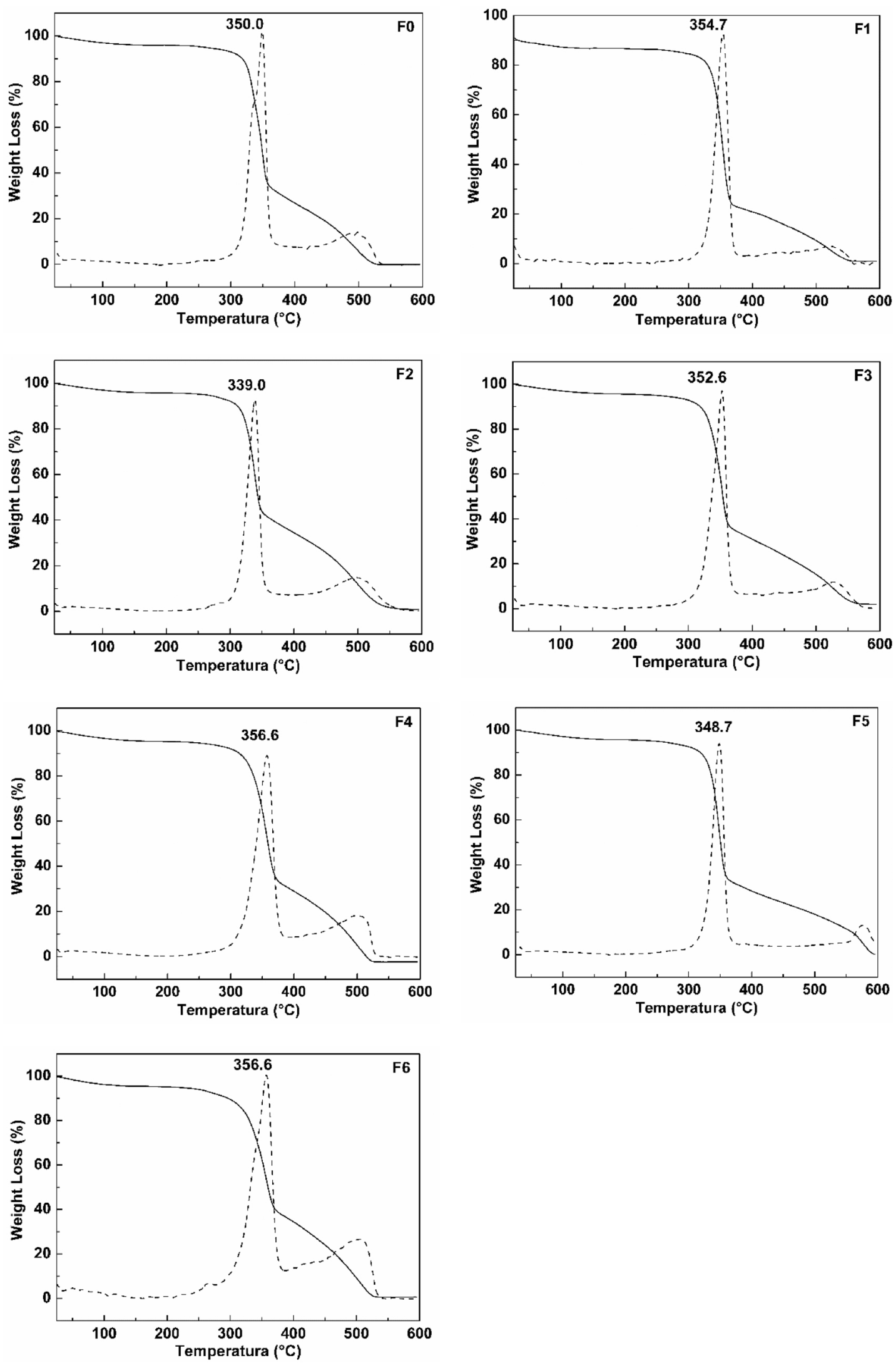

Fig. 6. Thermogravimetric (solid lines) and differential thermogravimetric (dashed lines) analysis of BC produced in distinct culture media, where F0 corresponds to BC produced from HS medium; F1 (50 g/L of glucose); F2 ( $40 \mathrm{~g} / \mathrm{L}$ of glucose plus $10 \mathrm{~g} / \mathrm{L}$ of SCM); F3 (30 g/L of glucose plus $20 \mathrm{~g} / \mathrm{L}$ of SCM); F4 (20 g/L of glucose plus $30 \mathrm{~g} / \mathrm{L}$ of SCM); F5 (10 g/L of glucose plus $40 \mathrm{~g} / \mathrm{L}$ of SCM) and F6 (50 g/L of SCM). 

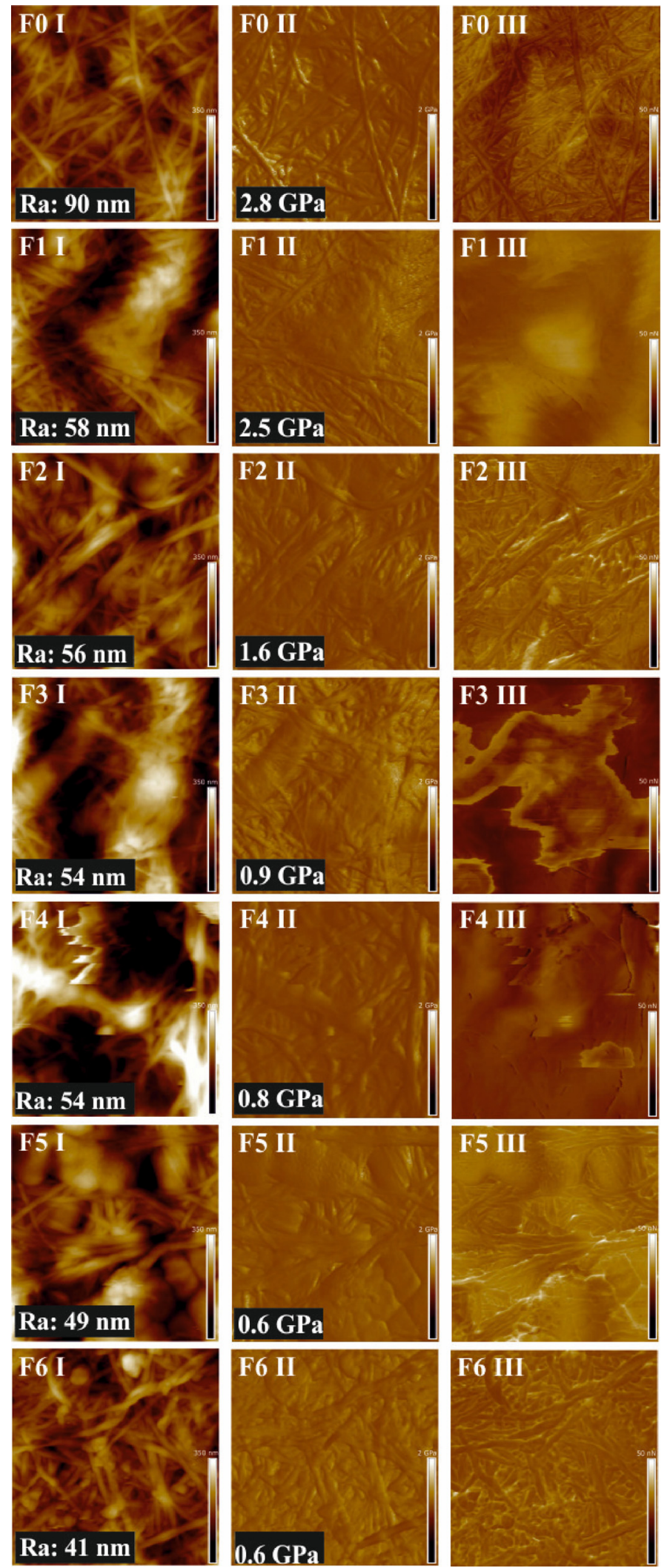

Fig. 7. PeakForce QNM images $(3 \mu \mathrm{m} \times 3 \mu \mathrm{m})$ of BC produced in distinct culture media, where F0 corresponds to BC produced from HS medium; F1 (50 $\mathrm{g} / \mathrm{L}$ of glucose); F2 (40 g/L of glucose plus $10 \mathrm{~g} / \mathrm{L}$ of SCM); F3 (30 g/L of glucose plus $20 \mathrm{~g} / \mathrm{L}$ of SCM); F4 (20 g/L of glucose plus $30 \mathrm{~g} / \mathrm{L}$ of SCM); F5 (10 g/L of glucose plus $40 \mathrm{~g} / \mathrm{L}$ of SCM) and F6 (50 g/L of SCM). I correspond to height, II to elastic modulus and III to adhesion PeakForce QNM images of each investigated BC membranes. 
investigated BC membranes, decrease with increase of SCM content in the culture media used for $\mathrm{BC}$ production. The $\mathrm{R}_{\mathrm{a}}$ of the $\mathrm{BC}$ membrane produced using HS culture media was $90 \mathrm{~nm}$, while the $R_{a}$ of the $B C$ membrane produced from glucose/SCM culture media decrease from $58 \mathrm{~nm}$ to $41 \mathrm{~nm}$ with increase of SCM content in the culture media. This phenomenon led to conclusion that the addition of SCM resulted in smoother BC membranes surface.

As can be observed from PeakForce QNM elastic modulus (Fig. 7F0II-F6II) and adhesion (Fig. 7F0III-F6III), surface mechanical properties of BC membranes changed in function of SCM content in the culture media. The average elastic modulus of the $\mathrm{BC}$ membrane produced form HS culture media, extracted from PeakForce QNM elastic modulus images of $3 \mu \mathrm{m} \times 3 \mu \mathrm{m}$, was equal to $2.8 \mathrm{GPa}$. Similar average elastic modulus was also detected for BC membranes produced from $50 \mathrm{~g} / \mathrm{L}$ of glucose $(\sim 2.5 \mathrm{GPa})$. The addition of SCM into culture media provoke decrease of the average elastic modulus, being $1.6 \mathrm{GPa}$ for culture media with $10 \mathrm{~g} / \mathrm{L}$ of SCM and $0.6 \mathrm{GPa}$ for culture media with $50 \mathrm{~g} / \mathrm{L}$ of SCM. Taken into account that addition of different $\mathrm{g} / \mathrm{L}$ of SCM change hydrogen bonds interaction, as confirm by FTIR, the decrease of the average elastic modulus with the increase of SCM in the culture media can be the consequence of the plasticization effect of the addition of SCM onto fabricated BC membrane.

\section{Conclusions}

Komagataeibacter rhaeticus bacterium was isolated of Kombucha tea and successfully grown in seven distinct static culture media in order to evaluate alternative carbon source for BC production. Physicochemical properties of the $\mathrm{BC}$ membranes labeled $\mathrm{F} 0$ (BC produced from HS medium), F1 (50 g/L of glucose), F2 $(40 \mathrm{~g} / \mathrm{L}$ of glucose plus $10 \mathrm{~g} / \mathrm{L}$ of SCM), F3 (30 g/L of glucose plus $20 \mathrm{~g} / \mathrm{L}$ of SCM), F4 (20 g/L of glucose plus $30 \mathrm{~g} / \mathrm{L}$ of SCM), F5 (10 g/L of glucose plus $40 \mathrm{~g} / \mathrm{L}$ of SCM) and F6 $(50 \mathrm{~g} / \mathrm{L}$ of SCM) were analyzed by FTIR, XRD, FEG-SEM, TGA and PeakForce (QNM-AFM) techniques. Results from FTIR, XRD and TGA measurements revealed that BC produced from distinct SCM-supplemented composition displayed similar features to those obtained from conventional Hestrin and Schramm media. Beyond that, TGA analysis displayed that all $\mathrm{BC}$ membranes were obtained without inorganic salts and impurities even using SCM without treatment. Morphological analysis showed three-dimensional BC nanofibers network independently on the culture media used for BC production. Additionally, increasing the SCM concentrations on culture media higher dense nanofibers were detected on BC membranes. Quantitative nanomechanical properties evaluated by AFM technique showed that increasing the SCM into culture media smoother and more flexible BC membranes surface were observed. Finally, the use of a by-product of Brazilian agroindustry without previous treatment as alternative culture media consist on a viable and promising strategy for reducing costs and enhancing BC production.

\section{Declaration of conflicts of interest}

The authors report no conflicts of interest associated with this publication.

\section{Funding}

This work was supported by FAPESP for financial support process 13/04948-9 linked to aid 11/51725-0; and the Brazilian agencies CNPq and CAPES. Financial support from Spanish Ministry of Economy and Competitiveness and European Union in the frame of MAT2015-66149$P$ project is gratefully acknowledged. Moreover, we are grateful to the Macrobehavior-Mesostructure-Nanotechnology SGIker unit of the UPV/ EHU.

\section{References}

Algar, I., Fernandes, S.C.M., Mondragon, G., et al., 2015. Pineapple agroindustrial residues for the production of high value bacterial cellulose with different morphologies. J. Appl. Polym. Sci. 131, 1-8.

Bae, S., Shoda, M., 2004. Bacterial cellulose production by fed-batch fermentation in molasses medium. Biotechnol. Progr. 20, 1366-1371.

Bae, S.O., Shoda, M., 2005. Production of bacterial cellulose by Acetobacter xylinum BPR2001 using molasses medium in a jar fermentor. Appl. Microbiol. Biotechnol. 67, 45-51.

Barud, H.S., Júnior, A.M.A., Santos, D.B., et al., 2008a. Thermal behavior of cellulose acetate produced from homogeneous. Thermochim. Acta 471, 61-69.

Barud, H.S., Barrios, C., Regiani, T., et al., 2008b. Self-supported silver nanoparticles containing bacterial cellulose membranes. Mater. Sci. Eng. C 28, 515-518.

Barud, H.S., Souza, J.L., Santos, D.B., et al., 2011. Bacterial cellulose/poly(3-hydroxybutyrate) composite membranes. Carbohydr. Polym. 83, 1279-1284.

BRASIL-Ministério da Agricultura, 2016. Pecuária e Abastecimento. Sistema de Acompanhamento de Produção Canavieira. (Accessed 16 November 2016). http:// www.agricultura.gov.br/vegetal/culturas/cana-de-acucar.

Çakar, F., Özer, I., Özhan Aytekin, A., et al., 2014. Improvement production of bacterial cellulose by semi-continuous process in molasses medium. Carbohydr. Polym. 106, $7-13$.

Castro, C., Zuluaga, R., Putaux, J.-L., et al., 2011. Structural characterization of bacterial cellulose produced by Gluconacetobacter swingsii sp. from Colombian agroindustrial wastes. Carbohydr. Polym. 84, 96-102.

Chawla, P.R., Bajaj, I.B., Survase, S.A., et al., 2009. Microbial cellulose: fermentative production and applications. Food Technol. Biotechnol. 47, 107-124.

Czaja, W., Krystynowicza, A., Bieleckia, S., et al., 2006. Microbial cellulose-the natural power to heal wounds. Biomaterials 27, 145-151.

De Salvi, D.T.B., Barud, H.S., Treu-Filho, O., et al., 2014. Preparation, thermal characterization, and DFT study of the bacterial cellulose triethanolamine system. J. Therm. Anal. Calorim. 118, 205-215.

Dos Santos, R.A.C., Berretta, A.A., Barud, H.S., et al., 2014. Draft genome sequence of Komagataeibacter rhaeticus strain AF-1, a high producer of cellulose, isolated from Kombucha tea. Genome Announc. 2, 1-2.

Grande, C.J., Torres, F.G., Gomez, C.M., et al., 2009. Nanocomposites of bacterial cellulose/hydroxyapatite for biomedical applications. Acta Biomater. 5, 1605-1615.

Hestrin, S., Schramm, M., 1954. Synthesis of cellulose by Acetobacter xylinum. II. Preparation of freeze-dried cells capable of polymerizing glucose to cellulose. Biochem. J. 58, 345-352.

Hungund, B., Prabhu, S., Shetty, C., et al., 2013. Production of bacterial cellulose from Gluconacetobacter persimmonis GH-2 using dual and cheaper carbon sources. J. Microb. Biochem. Technol. 5, 31-33.

Jahan, F., Kumar, V., Saxena, R.K., 2018. Distillery effluent as a potential medium for bacterial cellulose production: a biopolymer of great commercial importance. Bioresour. Technol. 250 (9), 22-926.

Jorfi, M., Foster, E.J., 2015. Recent advances in nanocellulose for biomedical applications. J. Appl. Polym. Sci. 132, 1-19.

Jozala, A.F., Pértile, R.A.N., Santos, C.A., et al., 2015. Bacterial cellulose production by Gluconacetobacter xylinus by employing alternative culture media. Appl. Microbiol. Biotechnol. 99, 1181-1190.

Keshk, S.M., 2014. Bacterial cellulose production and its industrial applications. J. Bioprocess. Biotech. 4, 1-10.

Klemm, D., Heublein, B., Fink, H.P., et al., 2005. Cellulose: fascinating biopolymer and sustainable raw material. Angew. Chem. 44, 3358-3393.

Kolakovic, R., Peltonen, L., Laukkanen, A., et al., 2012. Nanofibrillar cellulose films for controlled drug delivery. Eur. J. Pharm. Biopharm. 82, 308-315.

Lazarini, S.C., De Aquino, R., Amaral, A.C., et al., 2016. Characterization of bilayer bacterial cellulose membranes with different fiber densities: a promising system for controlled release of the antibiotic ceftriaxone. Cellulose 23, 737-748.

Lin, S.-P., Huang, Y.-H., Hsu, K.-D., et al., 2016. Isolation and identification of celluloseproducing strain Komagataeibacter intermedius from fermented fruit juice. Carbohydr. Polym. 151, 827-833.

Machado, R.T.A., Gutierrez, J., Tercjak, A., et al., 2016. Komagataeibacter rhaeticus as an alternative bacteria for cellulose production. Carbohydr. Polym. 152, 841-849.

Pacheco, G., Nogueira, C.R., Meneguin, A.B., et al., 2017. Development and characterization of bacterial cellulose produced by cashew tree residues as alternative carbon source. Ind. Crops Prod. 107, 13-19.

Paterson-Beedle, M., Kennedy, J.F., Melo, F.A.D., et al., 2000. A cellulosic exopolysaccharide produced from sugarcane molasses by a Zoogloea sp. Carbohydr. Polym. 42, 375-383.

Pinto, F.C.M., De-Oliveira, A.C.A.X., De-Carvalho, R.R., et al., 2016. Acute toxicity, cytotoxicity, genotoxicity and antigenotoxic effects of a cellulosic exopolysaccharide obtained from sugarcane molasses. Carbohydr. Polym. 137, 556-560.

Premjet, S., Premjet, D., Ohtani, Y., 2007. The effect of ingredients of sugar cane molasses on bacterial cellulose production by Acetobacter xylinum ATCC 10245. J. Soc. Fiber Sci. Technol. Jpn. 63, 190-193.

Rani, M.U., Apppaiah, K.A.A., 2013. Production of bacterial cellulose by Gluconacetobacter hansenii UAC09 using coffee cherry husk. J. Food Sci. Technol. 50, $755-762$.

Rani, M.U., Udayasankar, K., Anu Appaiah, K.A., 2011. Properties of bacterial cellulose produced in grape medium by native isolate Gluconacetobacter sp. J. Appl. Polym. Sci. 120, 2835-2841.

Segal, L., Creely, J., Martin, A., et al., 1959. An empirical method for estimating the degree of crystallinity of native cellulose using the X-ray diffractometer. Text. Res. J. 
29, 786-794.

Sheykhnazari, S., Tabarsa, T., Ashori, A., et al., 2011. Bacterial synthesized cellulose nanofibers; effects of growth times and culture mediums on the structural characteristics. Carbohydr. Polym. 86, 1187-1191.

Shezad, O., Khan, S., Khan, T., et al., 2010. Physicochemical and mechanical characterization of bacterial cellulose produced with an excellent productivity in static conditions using a simple fed-batch cultivation strategy. Carbohydr. Polym. 82, 173-180.

Tercjak, A., Gutierrez, J., Barud, H.S., et al., 2015. Nano- and macroscale structural and mechanical properties of in situ synthesized bacterial cellulose/PEO-b-PPO-b-PEO biocomposites. ACS Appl. Mater. Interfaces 7, 4142-4159.

Tercjak, A., Gutierrez, J., Barud, H.S., et al., 2016. Switchable photoluminescence liquid crystal coated bacterial cellulose films with conductive response. Carbohydr. Polym. 143, 188-197.
Tsouko, E., Kourmentza, C., Ladakis, D., et al., 2015. Bacterial cellulose production from industrial waste and by-product streams. Int. J. Mol. Sci. 16, 14832-14849.

Tyagi, N., Suresh, S., 2013. Isolation and characterization of cellulose producing bacterial strain from orange pulp. Adv. Mater. Res. 626, 475-479.

Tyagi, N., Suresh, S., 2016. Production of cellulose from sugarcane molasses using Gluconacetobacter intermedius SNT-1: optimization \& characterization. J. Clean. Prod. 112, 71-80.

Vazquez, A., Foresti, M.A., Cerrutti, P., et al., 2013. Bacterial cellulose from simple and low cost production media by Gluconacetobacter xylinus. J. Polym. Environ. 21, 545-554.

Velásquez-Riaño, M., Bojacá, V., 2017. Production of bacterial cellulose from alternative low-cost substrates. Cellulose 24, 2677-2698. 